\title{
Experimental Teaching System of Rail Transportation Signal and Control
}

\author{
Zheng Danyang*, Zhang Xiaoyu, Wang Chenxi, Li Liming \\ School of Urban Railway Transportation, Shanghai University of Engineering Science, Shanghai, China \\ Email address: \\ zdy199701@qq.com (Zheng Danyang),15615876508@163.com (Zhang Xiaoyu), 18871231089@163.com (Wang Chenxi), \\ liming0028@126.com (Li Liming) \\ ${ }^{*}$ Corresponding author
}

\section{To cite this article:}

Zheng Danyang, Zhang Xiaoyu, Wang Chenxi, Li Liming. Experimental Teaching System of Rail Transportation Signal and Control. Science Innovation. Vol. 7, No. 6, 2019, pp. 164-170. doi: 10.11648/j.si.20190706.13

Received: November 2, 2019; Accepted: December 9, 2019; Published: December 12, 2019

\begin{abstract}
Aiming at a series of issues about"Rail Transportation Signal and Control", such as abstract knowledge, practice workable,lack of experimental resources and low performance, a set of teaching practice system is designed, which takes rail transportation signal and control as the concept, embedded system as the core and interlocking concept as the essence. In combination with the course content, a series of professional experiments such as equipment control, route arrangement, interlocking verification, train control and other professional experiments are implemented. In the experiment teaching link, the "experimental teaching system of rail transportation signal and control" as the platform, the MCU was applicated in the experimental teaching, and combined with the vehicle control system, which was not only to achieve the basic working principle of the equipment and master, at the same time, further understanded of the concepts of interlocking, block, and so on. This experiment system is well known for its rich contents, effect of intuitive and strong repeatability. It is helpful for students to understand and master the knowledge points, which can improve the teaching effect and teaching quality.
\end{abstract}

Keywords: Rail Transit Signal and Control, Embedded, Interlocking, Experiment System, Automatic Train Supervision (ATS)

\section{轨道交通信号与控制教学实验系统}

郑丹阳", 张晓宇, 汪晨曦, 李立明

上海工程技术大学城市轨道交通学院, 上海, 中国

\section{邮箱}

zdy199701@qq.com (郑丹阳)，15615876508@163.com(张晓宇)，18871231089@163.com（汪晨燨）, liming0028@126.com（李立明）

摘要：针对“轨道交通信号与控制”知识点抽象、实践操作性强、实践资源匮乏、教学效果不佳等一系列问题，设计了 一套以轨道交通信号与控制为理念、嵌入式系统为核心、联锁概念为精髓的教学实验系统。结合课程内容, 以编程实 现设备控制、进路排列、联锁验证、列车控制等一系列专业类实验。在课程实验教学环节中，以“轨道交通信号与控制 教学实验系统”为平台，引入单片机编程控制技术，不仅实现了对轨道信号系统基础设备工作原理与控制过程的掌握， 同时结合车辆控制系统进一步加深了对联锁、闭塞等概念的理解与掌握。该实验系统内容丰富、效果直观、可重复性 强, 有助于学生对课程知识点理解和掌握, 从而改善教学效果、提高教学质量。

关键词: 轨道交通信号与控制, 嵌入式, 联锁, 实验系统, 列车自动监控系统 


\section{1. 引言}

截至2018年末, 我国累计 36 个城市建成投运城市轨道 交通线路169条，运营线路达5495公里，预计到2020年“十 三五”结束时, 我国城市轨道交通总里程将达到6000公里 [1]。根据国际城市轨道交通行业人才配备标准, 建设一公 里城市轨道交通线路, 至少需要60名管理及技术人员 [2], 随着我们轨道交通的大力发展, 对该领域的专业人才需求 将达到井喷状态。轨道交通信号与控制专业2013年全国开 始本科招生, 目前全国陆续已有 60 余所高校招生, 在专业 招生规模日益扩大的趋势下, 轨道信号设备、联锁、列控 等关键技术专业实验教学改革却处于滞后状态, 目前通过 到轨道交通运营单位的实地参观学习等形式加以弥补, 由 于受实习单位设备数量、安全生产等因素等制约, 无法让 真正让学生亲自动手操作, 形成了“形式学习”, 造成“产
学脱节”现象, 关键原因在于符合轨道交通信号与控制理 念的专业化、小型化、平台化的试验设备尚未出现 [3-6]。 根据本科新一轮教学改革计划, 如“卓越工程师计划”、“工 程教育认证”等, 如何提高对本专业学生对轨道交通信号 技术、自动化、电子电路技术、嵌入式技术等核心课程的 理解与掌握程度, 是一个亟需解决的难题[7]。

“轨道交通信号与控制教学实验系统”以嵌入式开发 箱为核心, 精心设计组织实验内容与方案, 将轨道交通信 号与控制理论教学变得直观化、具体化、形象化, 通过实 践教学将理论知识加以强化升华, 同时兼顾本专业对传统 电子技术、嵌入式系统开发类课程的特殊实验需求。该教 学实验系统如图1和图2所示, 包括嵌入式学习系统、轨道 线路系统、车库系统、ATS系统、轨旁设备系统等 8 个子 系统。

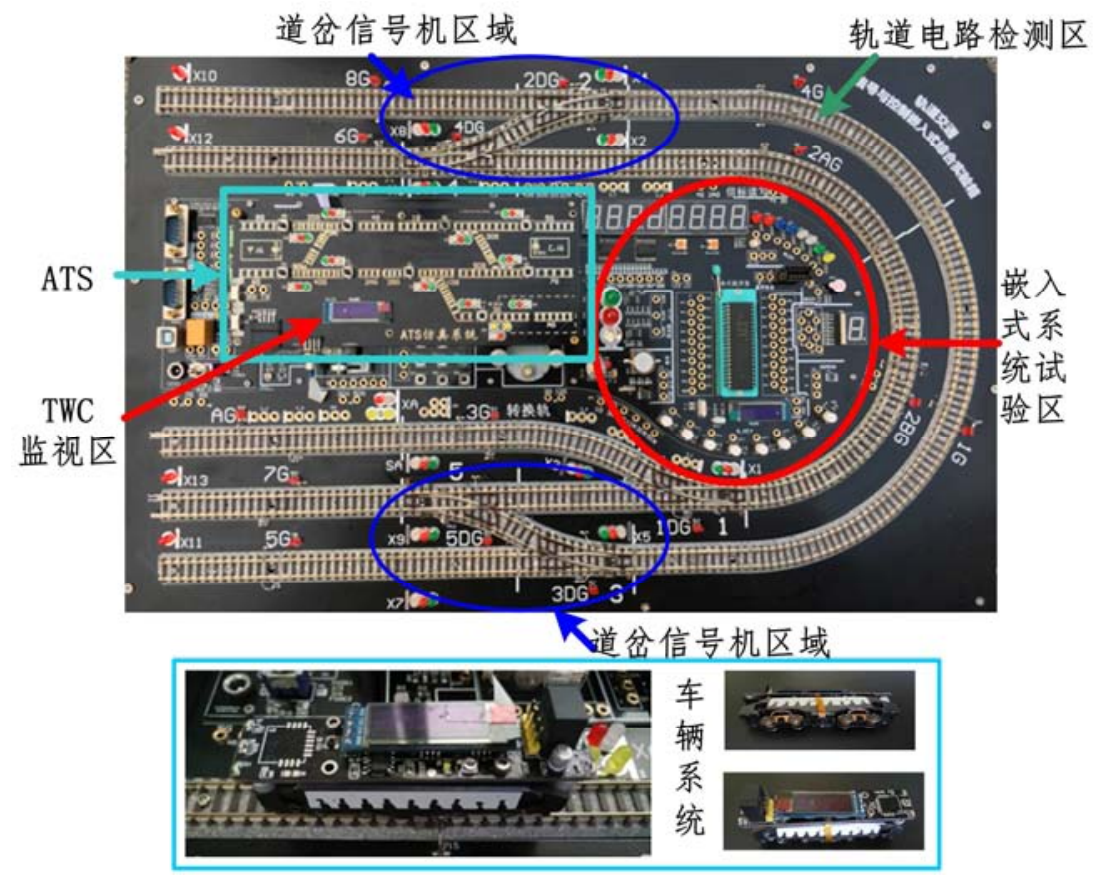

图1 轨道交通信号与控制教学实验系统实物图。

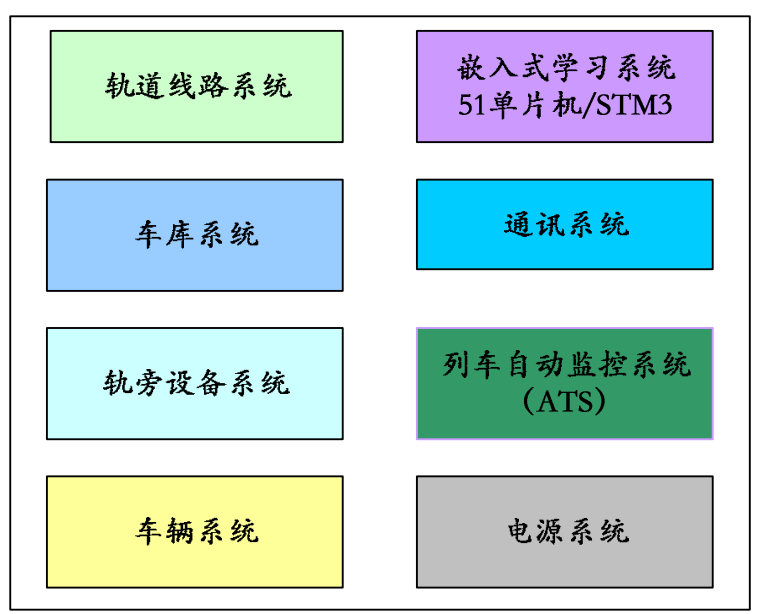

图2 轨道交通信号与控制教学实验系统框图。

\section{2. 整体设计}

\section{1. 仿真实验线路设计}

采用 $\mathrm{N}$ 比例 (1:160) 轨道线路模型, 包括 2 个虚拟岛 式车站、 1 个车库、转换轨、3组道岔区域以及多段轨道电 路, 轨旁设备主要设备包括: 转辙机、信号机、道岔、有 源/无源应答器等。整个线路功能满足车辆出入库作业、 列车调车作业、列车折返作业、车站停车作业等运营功能, 同时轨旁设备既可以实现轨道电路状态检测、转辙机定操 /反操、信号机点灯、信标信息读取的独立设备控制, 也 可以实现多设备的联合控制。该部分各个功能模块独立, 对外开放实验编程接口。 


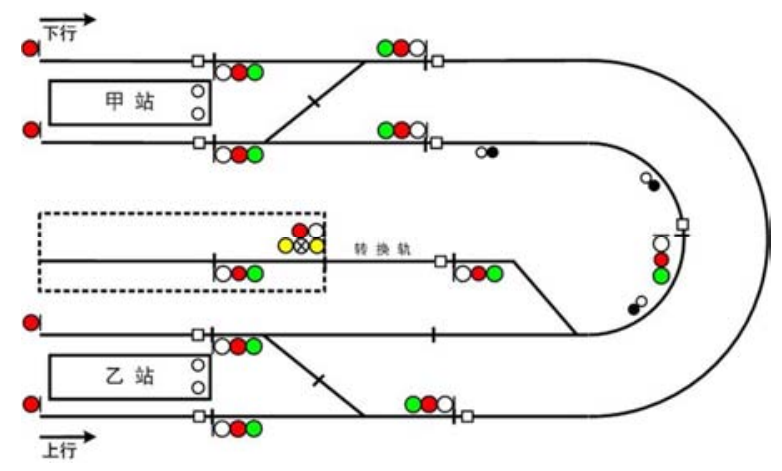

图3 实验线路图。

\section{2. 车辆系统}

车辆系统采用 $\mathrm{N}$ 比例轨道车辆模型, 如图4所示, 采用 轨道供电方式, 通过车载控制系统, 可以实现车速调整、 车速测量、运行方向调整、站台精确停车、车辆TWC通信、 信标读取等功能。车载系统采用STC15W系列单片机控制, 该型单片机电压工作范围宽, 不须任何转换芯片, 可直接 通过电脑USB接口进行ISP下载编程, 集成了更多的 SRAM ( $4 \mathrm{~K}$ 字节) 、定时器 7 个 ( 5 个普通定时器 $+C C P$ 定时器2)、串口 (4个), 同时集成更多的高性能部件 (如 比较器、带死区控制的6路15位专用PWM等), 相较STC51 系列单片机功能更强大 $[8]$ 。

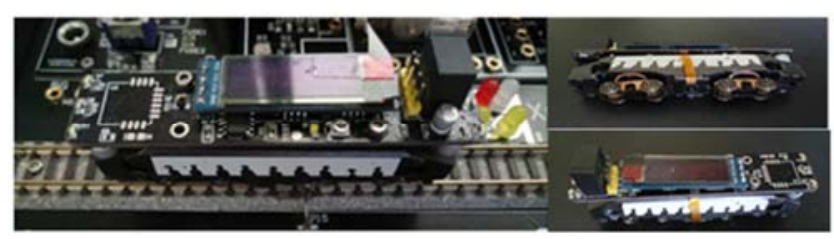

图4 车辆及控制系统。

\section{3. 轨道电路系统}

轨道电路是轨道交通信号的重要基础设备 [9-10], 以 线路的两根钢轨作为导体, 两端加以机械绝缘(或电气绝 缘), 接上送电和受电设备构成的电路, 限流电阻的作用 是保护电源不致因过负荷而损坏, 同时保证列车占用轨道 电路时, 轨道继电器可靠落下, 轨道电路的性能直接影响 行车安全和运输效率, 实验轨道电路模型与检测模块如图 5 和图6所示。

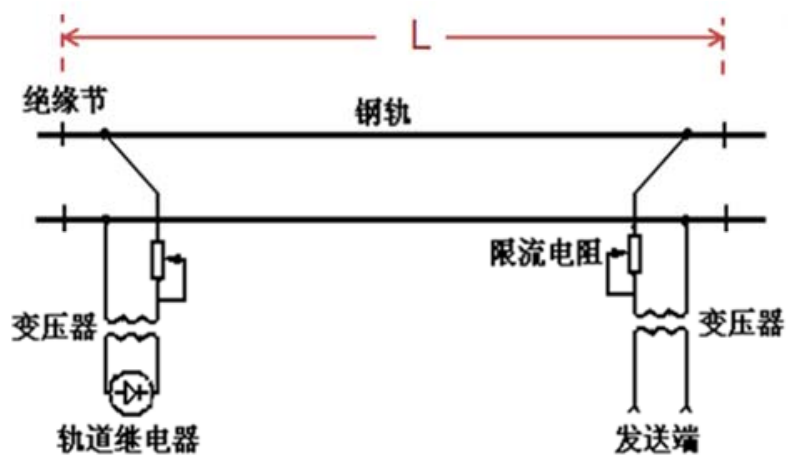

图5 实验轨道电路模型示意图。

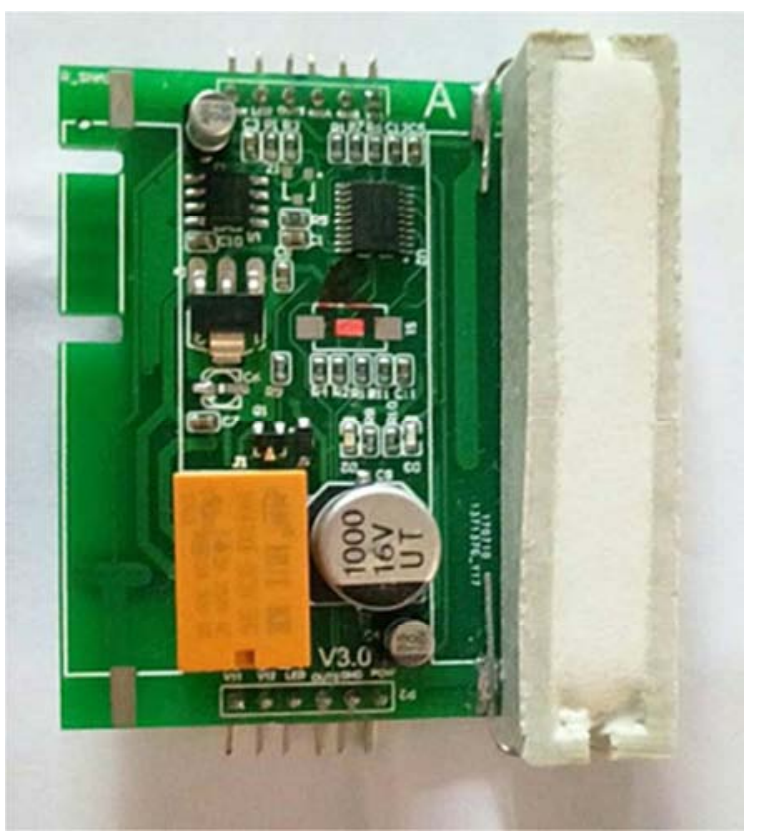

图6 实验轨道电路与检测模块实物图。

\section{4. 列车自动监控系统}

列车自动监控 (ATS) 系统, 是指挥列车运行的控制、 监督设备[11]。本教学实验ATS主要完成列车的调度跟踪、 列车的进路的控制和表示。以嵌入式编程控制, 通过按钮 实现列车进路选择, LED灯表示信号机指示状态, LED光 带表示轨道电路区段状态、道岔区段位置状态, 同时兼顾 发车表示灯指示功能。

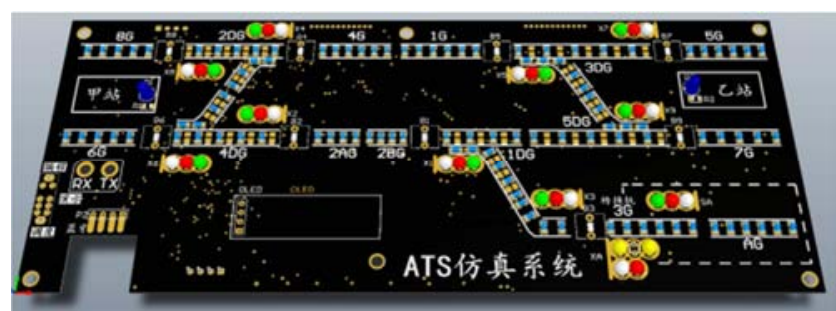

图7 ATS效果图。

\section{3. 实验设计}

轨道交通信号与控制基础教学内容涉及到传感器测 量原理、计算机原理及应用技术、电子信息技术、自动控 制理论、轨道交通控制技术等多方面工程应用知识 [11]。 同时要求学生掌握轨道交通信号系统基础设备如: 如信号 机、转辙机、轨道电路、计轴设备、应答器等的基本结构、 工作原理、现场应用原则; 同时掌握车站、区间、联锁、 闭塞等基本概念。本实验系统根据课程内容, 并结合学生 特点及培养要求, 精心组织设计实验内容, 体现出不同的 层次, 满足学生对该课程各阶段学习的不同要求。实验系 统分为基础性实验与专业性实验两大部分, 其中基础性实 验满足嵌入式课程 (如单片机) 教学实验, 专业性实验包 括: 基础验证性实验与综合设计性实验两部分, 具体实验 设计如图8所示。 


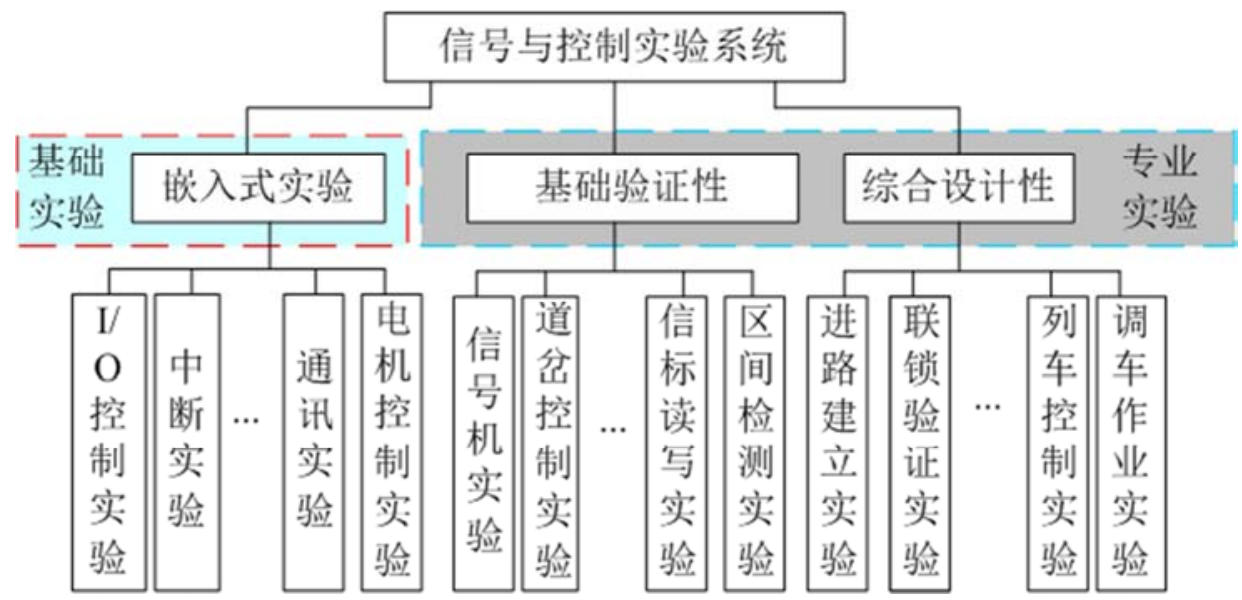

图8 实验教学课程设计。

\section{1. 实验教学案例—轨道电路实验}

轨道电路是以钢轨作为导体, 两端加上机械绝缘 (或 电气绝缘), 接上送电和受电设备构成的电路, 是信号系 统的基础设备之一。轨道电路主要用于监督线路的占用情 况, 并可以向列车传输控制信息, 将列车运行和信号显示 等联系起来。对于城市轨道交通, 轨道电路是信号系统的 重要基础设备, 直接影响行车安全和运输效率[12]。

轨道电路进行监督列车在正线或列车和车辆在车辆 段等线路的占用状态。轨道电路反映有关线路空闲时, 为 开放信号、建立进路、构成闭塞提供了依据; 轨道电路被 占用时, 用于实现控制有关信号机的自动关闭, 实现信号 系统的自动控制。通过编程利用嵌入式单片机 $\mathrm{I} / \mathrm{O}$ 采集轨 道电路检测模块状态量的变化, 实现对轨道电路调整状态、 分路状态、断轨状态的检测功能, 同时还具备向列车传输 行车信息的能力 [13], 达到掌握轨道电路工作原理的目的。 轨道电路状态检测的程序流程图如图9所示。

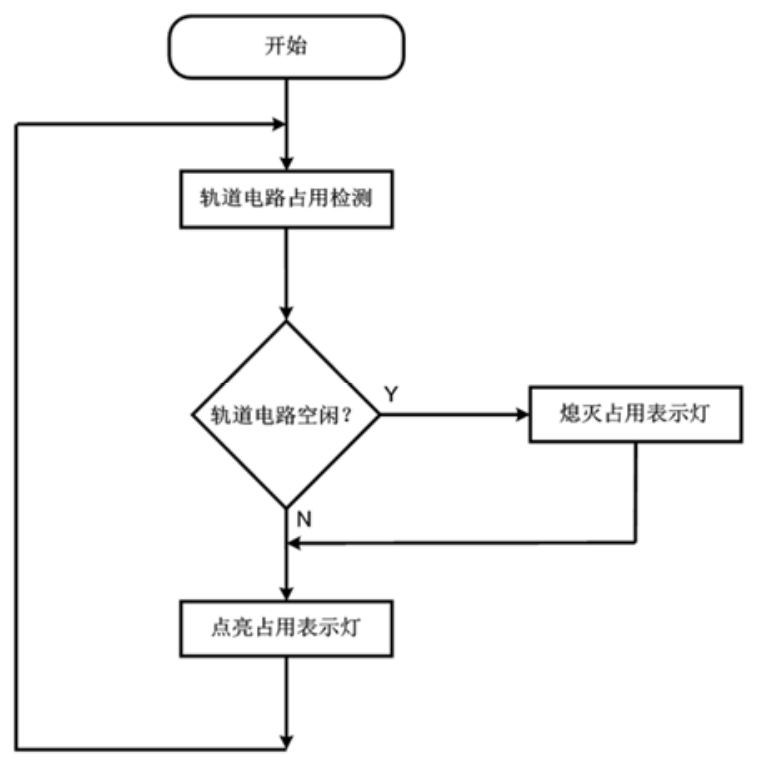

图9 轨道电路检测流程图。

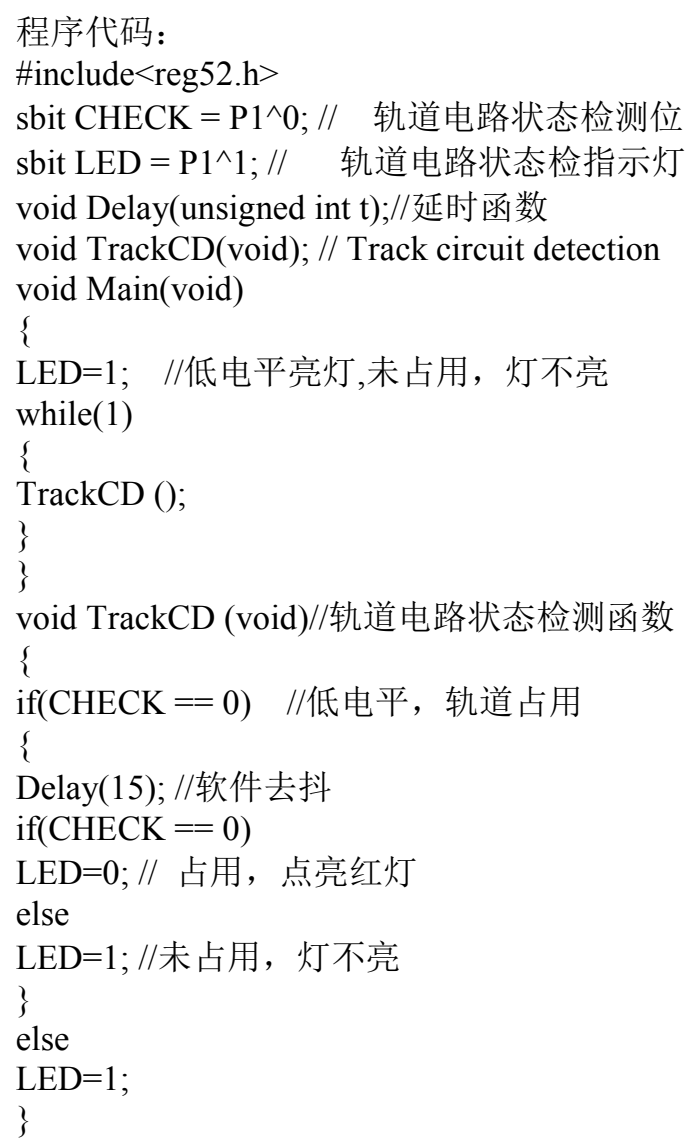

\section{2. 实验教学案例一联锁验证实验}

联锁是指车站内信号机、道岔、进路（轨道区段）, 这三者必须建立的一种制约关系称为联锁关系 [14], 其主 要功能是确保车站内列车经过道岔时的运行安全。其中进 路是指列车运行的路径; 道岔用于决定列车运行的进路; 信号机用于防护列车运行的进路。根据站场布置图（图 1-1），实验站场联锁关系简表如表1。 
表1 联锁表。

\begin{tabular}{lllllll}
\hline 进路号 & 进路 & 按钮 & 信号机显示 & 道岔位置 & 敌对信号 & 轨道区段 \\
\hline 1 & 直向 & 始端按钮+侧向进路终端按钮 & 绿 & 定位 & - & 区段1 \\
2 & 侧向 & 始端按钮+直向进路终端按钮 & 白 & 反位 & - & 区段1 \\
\hline
\end{tabular}

列车运行通过有岔区段的过程如下:

1. 建立进路以控制道岔到进路所需要的位置, 并将进路 上的所有道岔锁闭;

2. 检查信号开放为允许信号的条件以后, 开放相应的信 号机;

3. 列车进入信号机内方以后, 信号自动关闭, 变为红色 显示;

4. 列车按所建立的进路通过以后, 在满足“三点检查” 的前提下，使进路上的道岔，自动地“逐段解锁”。
本实验是在完成上述过程第一点的基础上, 完成信号 开放、进路解锁后续步骤。

本实验重点体现进路（轨道区段）和信号机，道岔和 信号机之间的关系。从上表可以观察到, 在进路内方所有 轨道区段处于空闲时, 且道岔处于进路规定位置且被锁闭 时, 信号机才能根据进路上的道岔实际位置开放对应信号。 一旦道岔、轨道区段任一条件不满足, 信号应立即关闭 (由 于设计限制，对于敌对信号条件本实验暂不作考虑）。

根据上述原理, 当办理直向进路且道岔锁闭后, 信号 机显示绿灯，如图10所示:

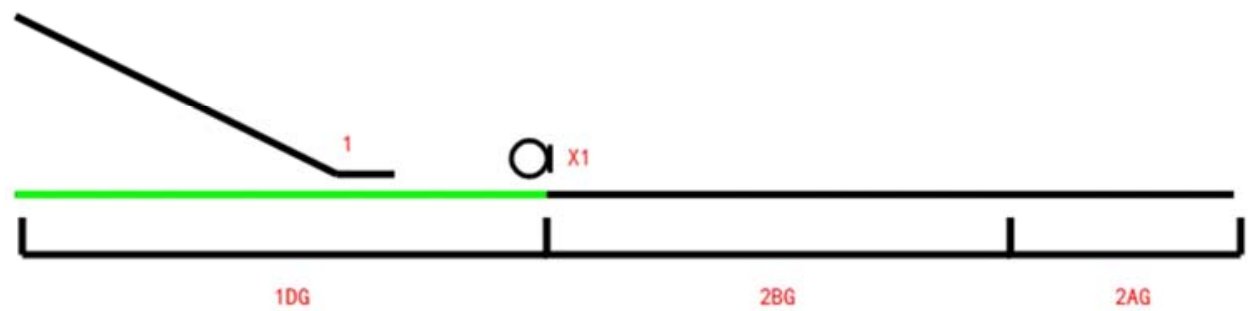

图10 办理直向进路区段图。

当办理侧向进路且道岔锁闭后, 信号机显示, 白灯如图11所示:

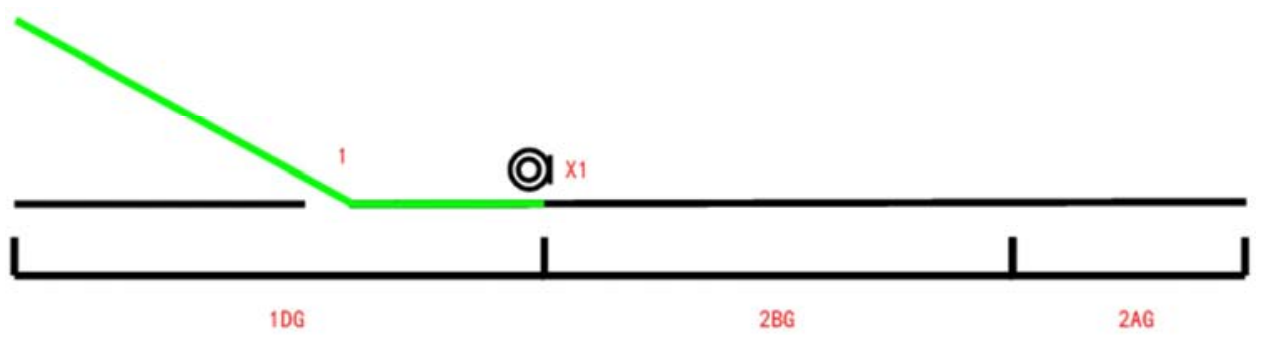

图11 办理侧向进路区段图。

根据联锁相关原理, 联锁验证程序流程图, 如图12所示。

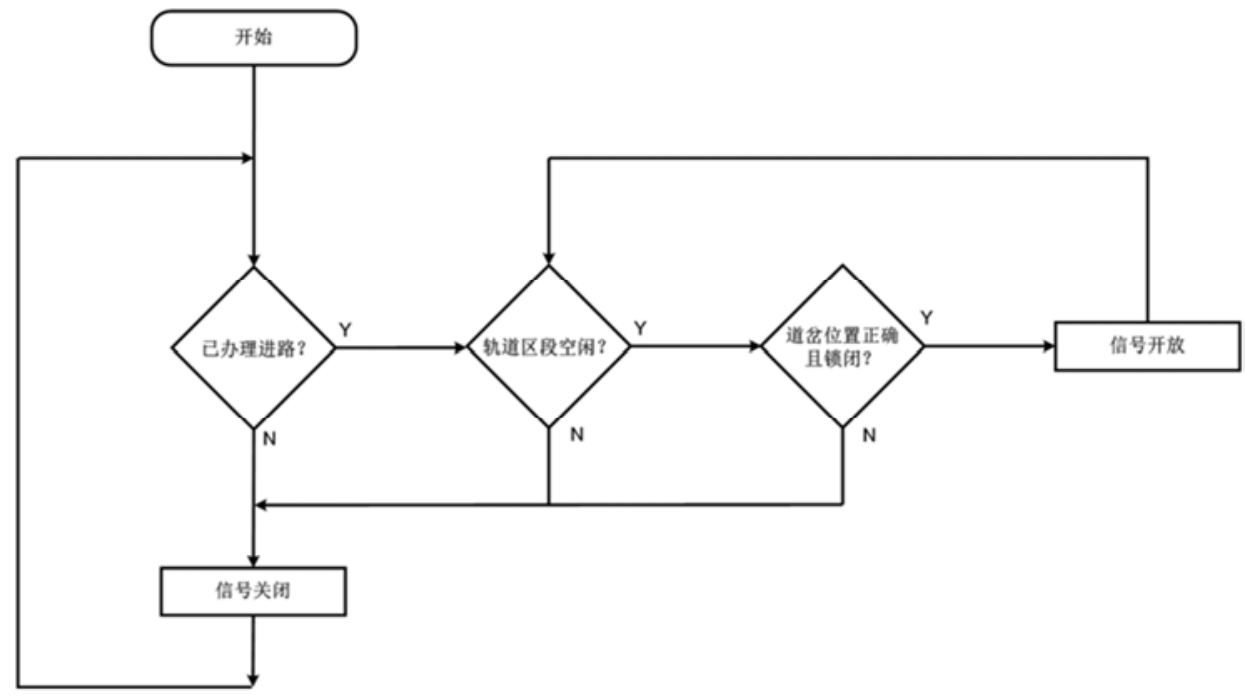

图12 联锁验证程序流程图。 


\section{3. 实验教学案例一进路解锁实验}

进路是指在车站内列车或调车从一个地点运行到另 一个地点所经过的路径。进路解锁是进路控制的一个步骤, 发生在进路建立之后。

本实验的任务是在进路控制的基础上，在进路建立、 道岔锁闭信号开放后, 列车通过进路正常解锁, 或取消已
排列的进路时, 通过人工解锁或取消进路操作, 方可使已 被进路锁闭的道岔解锁, 重新排列。

当信号开放后，进行正常通过解锁时，需列车按顺序 通过进路内方轨道区段，由联锁系统进行“三点检查”判断 后方可解锁 [15]。“三点检查”是指列车出清前一区段且前 一区段解锁、本区段占用后又出清、下一区段占用，满足 这样的条件下本区段自动解锁。
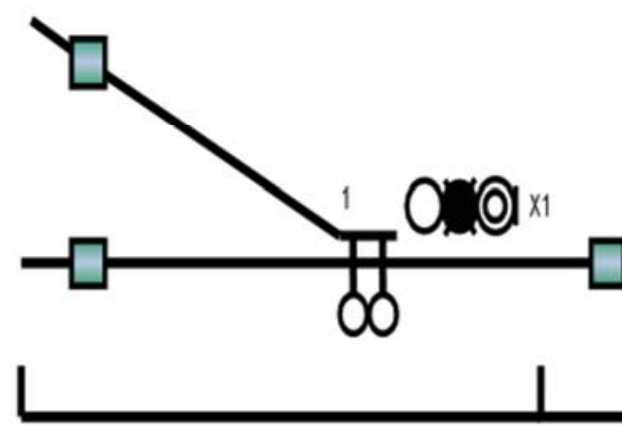

$10 G$

$2 B G$

$2 A G$

图13 轨道区段图。

如图13所示, 为某站场的局部区域图, 该区域包含一组 单动道岔, 转辙机通过相关杆件与道岔进行连接, 来实现道 岔位置的转换, 该区域由绝缘节被分成三个轨道区段: 有岔 区段1DG（区段1）、一接近区段2BG（区段2）、二接近区 段 $2 \mathrm{AG}$ (区段3）, 三个绿色按钮为进路选择按钮, 当列车经 过该区域时，各轨道区段的状态变化如表2所示，根据“三点 检查”的解锁条件，若想对区段 2 进行正常通过解锁，只有当 表2中所示的序号1到序号6的六种情况全部按顺序发送后, 区段2能解锁。进路解锁程序的流程图如图14所示。

表2 三点检查各阶段状态。

\begin{tabular}{llll}
\hline 序号 & 区段1 & 区段2 & 区段3 \\
\hline 1 & 占用 & 空闲 & 空闲 \\
2 & 占用 & 占用 & 空闲 \\
3 & 空闲 & 占用 & 空闲 \\
4 & 空闲 & 占用 & 占用 \\
5 & 空闲 & 空闲 & 占用 \\
6 & 空闲 & 空闲 & 空闲 \\
\hline
\end{tabular}

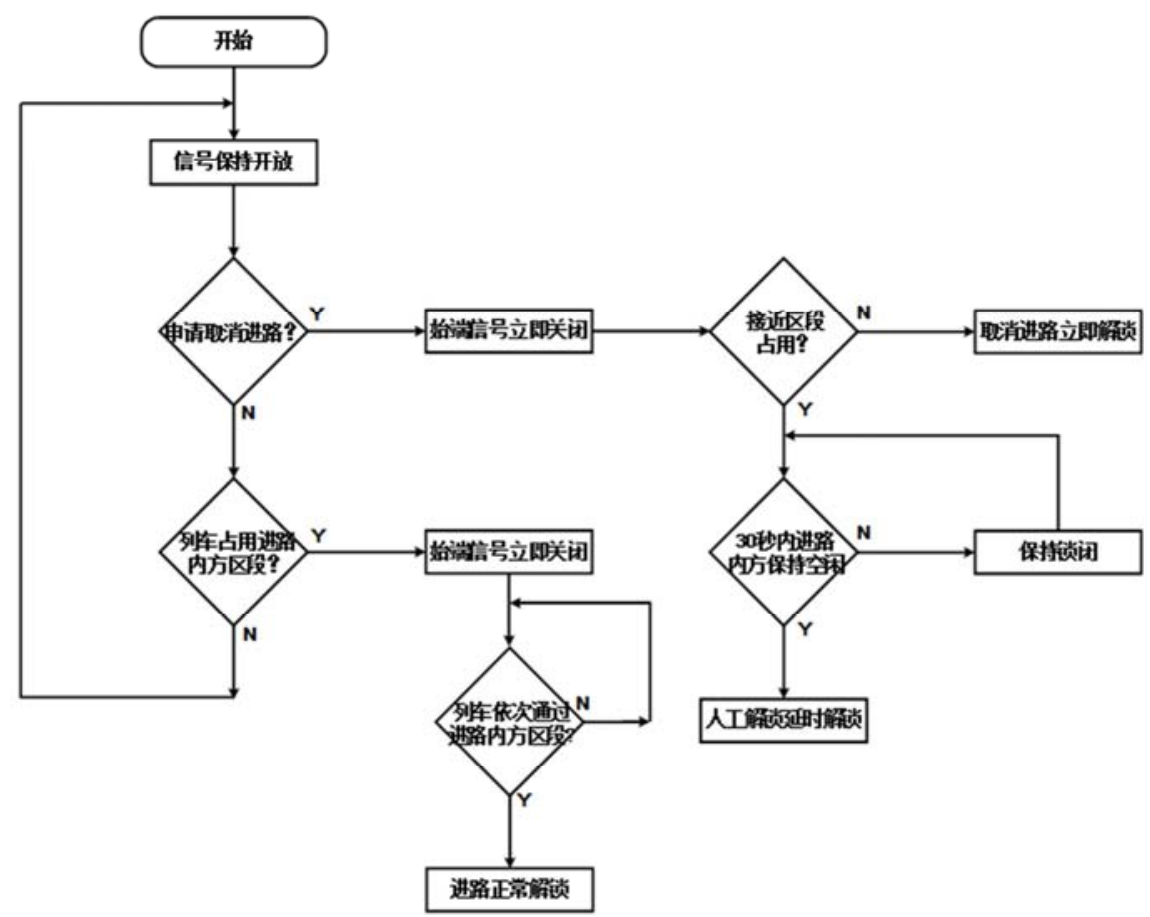

图14 进路解锁程序流程图。 


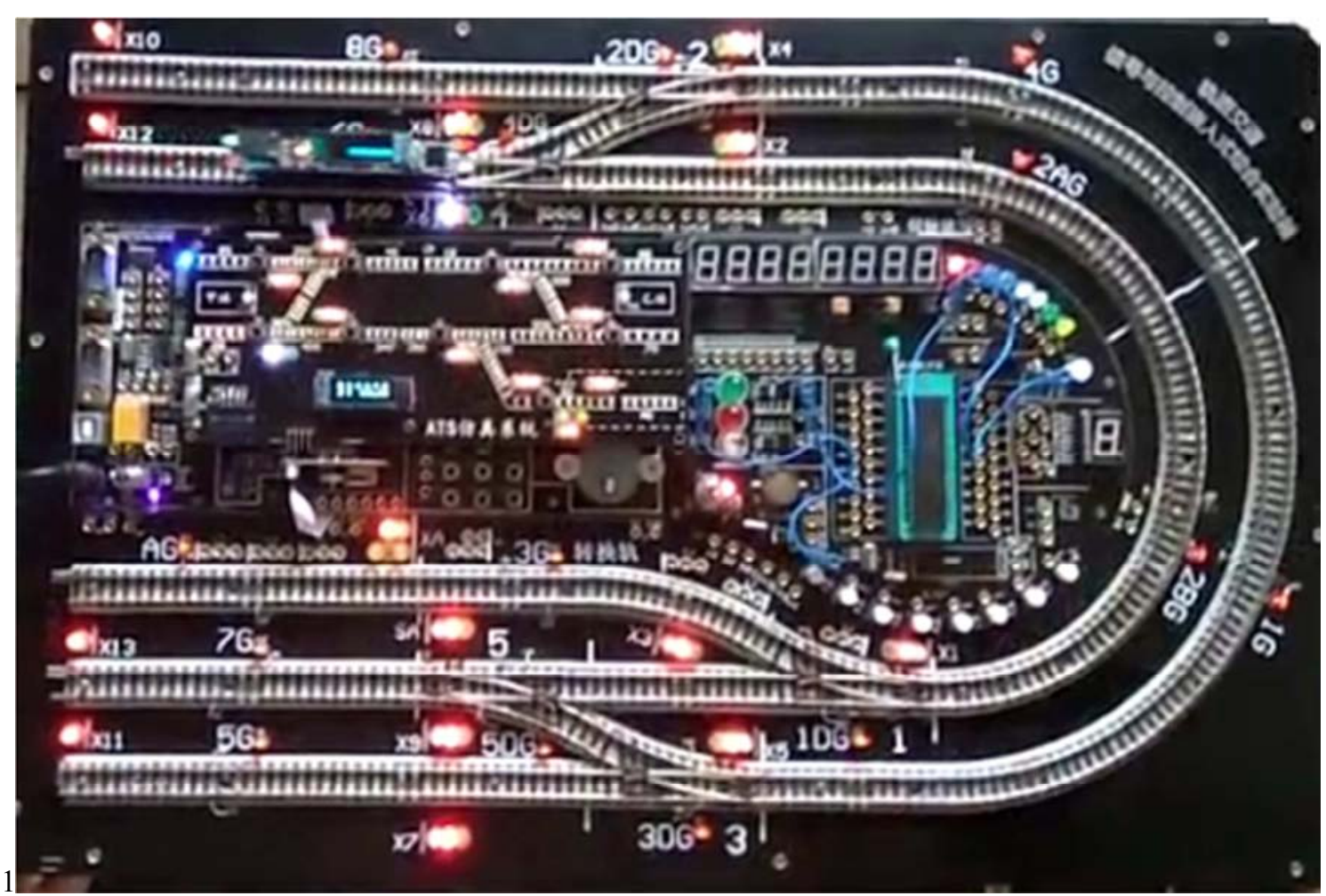

图15 实验效果展示图。

\section{4. 结论}

本教学实验系统是针对轨道交通信号与控制专业课 程实践设计开发的系统。本文从系统的整体设计和实验设 计两方面对系统进行了详细的介绍, 符合课程实践教学环 节的需要, 并根据教学要求的变化及时调整实验内容, 从 而建立完善的、多样的、符合现实要求的技术应用型教学 实验系统。

该教学实验系统丰富的实验资源, 专业的实验内容及 灵活的实验操作, 不仅满足了学对嵌入式的学习热情和钻 研精神, 提高他们的动手能力, 同时为学生提供了“理论 结合实际”的实验平台, 实现了技术与理论相结合, 使教 学变得直观化、具体化、形象化, 有助于提高轨道交通信 号与控制专业知识教学效果, 加深学生专业知识点的理解, 并有助于学生自主学习积极性的提高和创新意识的培养, 适应培养应用型人才的迫切需求。

\section{参考文献}

[1] 赵昕,顾保南.2018年中国城市轨道交通运营线路统计和分 析[J].城市轨道交通研究,2019,22(01):1-7.

[2] 郭婕.城市轨道交通运营管理专业人才需求分析[J].交通职 业教育,2014,4:17-19,32.

[3] 江志樹,洪玲,谢超.轨道交通调度与应急处置综合实验平台 设计 [J]. 实验技术与管理,2016,32(1):91-94,99.
[4] 徐晓滨,李世宝,孙新亚.ZPW-2000 A 轨道电路故障诊断实 验平台 $[J]$.实验技术与管理,2016,33(5):63-68.

[5] 孔勇,杜普选,谈振辉, 等. 铁路轨道信号发送与车载接收模拟 系统 [J].铁道学报,2011,33(3):66-70.

[6] 杨扬,郭进,王小敏,等. 铁路信号基础设备控制实验系统的 设计和实现[J].高校实验工作研究,2012(2):115-117.

[7] 刘伯鸿, 李国宁,陈永刚, 等. 构建铁路特色专业课程新体系 提高人才培养质量 [J]. 自动化与仪器仪表, 2013(04):218-219.

[8] 朱向庆,胡均万,陈宏华, 等.多功能单片机实验系统的研制 [J]. 实验室研究与探索,2012,31(4):41-44.

[9] 郎宗棪,郜成缙. 现代铁路信号技术[M].成都:西南交通大学 出版社, 2001.

[10] 郭进. 铁路信号基础设备 [M]. 成都: 西南交通大学出版 社,2008.

[11] 徐金祥. 城市轨道交通信号基础[M]. 北京: 中国铁道出版 社,2011. 2014,(22):225-226.

[12] 魏丽丽, 肖曼琳,王昊鸣.《城市轨道交通信号检测技术》课 程教学策略探究[J]. 科技咨询, 2016,27:116-117

[13] 谭丽娜.《城市轨道交通信号系统》课程项目化教学的研究 与实践 $[\mathrm{J}]$.教育教学论坛,

[14] 杨武东.轨道交通信号基础设备实验课程体系建设 $[\mathrm{J}]$.实验 科学与技术,2015,13(5):117-118,263.

[15] 林瑜筠. 铁路信号基础[M]. 北京:中国铁道出版社,2011. 